\title{
Definition of a Crowdsourcing Innovation Service for the European SMEs
}

\author{
Fábio Oliveira, Isabel Ramos, and Leonel Santos \\ University of Minho, Department of Information Systems, \\ Campus de Azurém, 4800-057 Guimarães, Portugal \\ fjroliveira@gavea.dsi.uminho.pt, iramos@dsi.uminho.pt, \\ leonel@dsi.uminho.pt
}

\begin{abstract}
Based on literature review and on the study of the most known and referred Crowdsourcing brokers, there's a clear trend to implement this model by large companies and mainly within the North American context. Our research team is focused in bringing this approach closer to the European culture, more specifically the cultural factors underlying the dynamics and motivation of communities available to solve the innovation challenges of Small and Medium Enterprises (SMEs), that we call Crowdsourcing Innovation. We believe that, due to the common lack of resources for innovation in these companies, a service capable of involving them in large networks filled with useful and reachable knowledge, and capable of supporting these companies through all the innovation process, is crucial to the future competitiveness of the European SMEs. Although our team is focusing on several aspects related to Crowdsourcing, my main research focuses the information services and supporting applications to create a web platform adapted to the key economical, organizational, legal and cultural differences that make current Crowdsourcing Innovation businesses less popular among European SMEs than in North America.
\end{abstract}

Keywords: Crowdsourcing Innovation, European SMEs, Intermediaries.

\section{Introduction}

There has been a large interest in the Open Innovation phenomenon and in the Crowdsourcing as an Open Innovation model by academics and practitioners. However, these studies and discussions have focused large, North-American companies.

There are a number of important factors that lead us to believe that the exploration of the Crowdsourcing Innovation model in the European SMEs can be of decisive importance in the near future. First of all, it has been said that Europe has a handicap in competitiveness, greatly related with a weak investment in innovation[1]. If we take into account that SMEs have great impact in the European economy, and that due to the lack of structure and resources, these companies usually don't have the capacity to have formal R\&D structures, then, it is easy to understand that these companies should be able to improve their innovation capabilities, and manage their innovation processes. They are forced to catch short windows of opportunities, often in collaboration with other SMEs or larger companies within their contacts network [2], [3] and [4]. 
Some authors consider that SMEs, being more flexible, have a competitive advantage against larger companies in radical innovations [5], and that this is the way to innovate in SMEs. But how many can generate radically new products? And for how long is such an advantage sustainable?

Based on these reflections, we believe that the use of the Crowdsourcing Innovation model by SMEs could be of great benefit. With the help of an adequate Crowdsourcing Innovation intermediary,these companies would be involved in a network able to generate useful and reachable ideas, knowledge and technology.Bybeing involved in such a wide and rich network, more new ideas can be generated, more new ideas can be turned into new or better products and more of these can reach the market.The intermediaries in the market today, at least the larger and most well-known, fail to support these companies. There is also a lack of scientific literature about these services. So, my main research goal is to define an adequate architecture for a Crowdsourcing Innovation intermediary service focusing the unique characteristics ofthe European SMEs.

The objective of this paper is to present and discuss my motivations, findings and future work. In this article we will present our vision of Crowdsourcing Innovation, our prediction of what a Crowdsourcing Innovation intermediary for the European SMEs should be and our future work to achieve the proposed goals.

\section{Crowdsourcing Innovation}

Open Innovation and Crowdsourcing have become "buzz words" and their application and concepts have been broad, being sometimes applied, maybe wrongly, to almost any kind of collaboration over the Internet. The purpose of the term Crowdsourcing Innovation is to narrow the scope of the term Crowdsourcing and to better specify our goal.

Open Innovation has appeared as the new and promising way of achieve and manage innovation, by opening up the firms' boundaries and letting ideas and technologies flow between the firm and its environment [6]. We understand Crowdsourcingas a way of outsourcing to the crowd tasks of intellectual assets creation [7], often collaboratively, with the aim of having easier access to a wide variety of skills and experience (as in Wikipedia). We focus on Crowdsourcing Innovation as a particular way to open up the innovation process, using large networks of individuals to access, capture and explore external knowledge, technologies and competencies, in other words to bring the "wisdom of crowds" into the company to help it innovate.This may lead us to question what really an Innovation is.

An Innovation is generally defined as a new way to do something. However, we like to take in consideration the ideas of Schumpeter, who defines inventions as new ways to do things, and innovations as inventions successfully applied in practice [8]. This means that an innovation should lead the company adopting it to a competitive advantage, either by cost or differentiation [9]. Sure that an invention is a step closer to an innovation, but it's still far from being an innovation. We believe that Crowdsourcing it not only useful in creating inventions (the first stages of the innovation process) but is also useful in converting them in innovations (the latter stages of the innovation processes). This turns even more important in SMEs, which, as stated earlier, due to the smaller structure have, normally, serious difficulties to complete the innovation process. 


\section{Crowdsourcing Innovation Service for European SMEs: Challenges and Opportunities}

The Open Innovation and Crowdsourcing Innovation models have been studied and applied mainly in large companies and the brokering services in market today reflect this trend. SMEs are typically the innovation and employment engines in society since they are usuallymore nimble and responsive to the business environment than the larger companies [10].Crowdsourcing Innovation model can add to that the access to a wide collective intelligence available as a result of the governments' investments in education, science and technology.However, this can only be true with the help of a specific intermediary capable of answering these companies' needs and specificities, since they usually do not possess the resources to manage a network of creative people and to deal with the many complexities associated with knowledge and technology transfer[11].

These companies are likely to consist of talented people, entrepreneurs with particular skill sets. However, these companies may lack the full range of skills or capabilities to complete large assignments or fully commercialize innovative solutions.Consequently brokering services must provide support to SMEs' needs along all the innovation process' stages, and pre-invention and post-innovation support must be considered,unlike the brokers specialized in the innovation needs of large companies. Also, smaller companies may lack legal and financial resources to adequately protect their intellectual property, unlike larger ones. Therefore, the networking and sharing of their innovation problems can be seen as risky. The crowdsourcing innovation intermediary has to be particularly trustable and must help these companies to protect their intellectual property and sensitive information [12]. Also the business model behind the most well-known brokers is largely supported by consulting activities to prepare companies to open up the Innovation process. This seems inadequate for SMEs since it may increase the costs of using intermediary services. The business model must be re-thought to address this difficulty, both by ensuring a high number of associated SMEs and by using present innovation infra-structures already in place in the world, and in special in Europe, namely Living Labs, Knowledge centers.

The European context carries extra challenges. Firstly, the European companies have several cultural differences; for instance they are known for being more averse to taking risks. This makes that Open Innovation is being met with resistance [13]. Also, the European patenting system is under developed if compared to the NorthAmerican.The motivators for the crowd may also be different since job mobility is different in Europe and career development is highly valued. This may indicate that reputation development and community sense may be even more important than financial rewards. Another aspect is to develop formal ways of acknowledging the relevance of contributions of crowd members by their employers, present or prospect .

\section{Research Plan}

This research is in an initial stage and the several relevant issues are still being studied. The research question guiding the future work is: "What is the adequate architecture of 
a web platform to support a Crowdsourcing Innovation intermediary service for the European SMEs?"

In order to answer this question the research will have three main conceptual focuses. First, it is necessary to deepen the understanding of the needs and specificities of the European SMEs' and the expectations they hold in embracing Crowdsourcing Innovation. Secondly, we want to understand the differences between the existing intermediaries based in the USA and those based in Europe, and to understand if these intermediaries act differently when dealing with SMEs and larger companies. To do so, we have already identified, based on [14], some intermediaries supporting Crowdsourcing Innovation in Europe that we will compare the most known intermediaries based in the North-America. Thirdly, we will study what motivates people to join the intermediary's network and how to best protect their intellectual property.

This project will be conducted as a Design Research project. As described by VaishnaviandKuechler[15], our work is currently in the end of the first phase, where this proposal is expected as an output. For the next phase, we expect to make several interviews to SMEs managers, and to representatives of existing Crowdsourcing Innovation intermediaries, to better understand their needs and expectations, and current platforms. Based on all previous work, a first version of a conceptual model for the web platform should be designed, and a prototype developed. This prototype will be deployed and promoted with the help of SMEs associations. The platform would be under evaluation, based on general utilization and the opinions of an expert panel, during a period of eighteen months. During this period the conceptual model of the web platform and the prototype will undergo all the perceived improvements, resulting in a validated conceptual model for a web platform supporting a Crowdsourcing Innovation Intermediary service for European SMEs.

The scientific contributes of this study will be the study and general conceptualization of the information services and technologies of a web platform of a Crowdsourcing Innovation intermediary service for SMEs. For practitioners, this work provides knowledge about the existing Crowdsourcing Innovation intermediaries and will empower them to improve their services. Hopefully, we expect the prototype developed in this project to evolve into a platform for an actual intermediary supporting innovation in SMEs being defined by several $\mathrm{PhD}$ projects: governance, risks, community, learning and memory, and knowledge repository.

\section{References}

1. Vigier, P.: Towards a Citizen-driven Innovation System in Europe: A governance approach for a European innovation agenda. Innovation 20(3), 191-202 (2007)

2. Edwards, T., Delbridge, R., Munday, M.: Understanding innovation in small and mediumsized enterprises: a process manifest. Technovation 25, 1119-1120 (2005)

3. Rothwell, R., Dodgson, M.: Innovation and size of firm. In: Dodgson, M. (ed.) Handbook of Industrial Innovation, pp. 310-324. Edward Elgar Publishing Limited, Aldershot (1994)

4. Rothwell, R.: External networking and innovation in small and mediumsizedmanufacturing firms in Europe. Technovation 11(2), 93-112 (1991)

5. Laursen, K., Salter, A.J.: Searching high and low: what type of firms use universitiesas a source of innovation? Research Policy 33(8), 1201-1215 (2004) 
6. Chesbrough, H.W.: Open innovation: the new imperative for creating and profiting from technology. Harvard Business School Press, Boston (2003)

7. Howe, J.: The Rise of Crowdsourcing. Wired Magazine, 176-183 (2006)

8. Schumpeter, J.: The Theory of Economic Development. Harvard University Press, Boston (1934)

9. Porter, M.E.: Competitive Advantage. The Free Press, New York (1985)

10. Dicken, P.: Global shift: Mapping the changing contours of the world economy. Sage, London (2007)

11. Ramos, I., Cardoso, M., Carvalho, J.V., Graça, I.: An action research on open knowledge and technology transfer. In: Proceedings of the Conference The role of IS in leveraging the intelligence and creativity of SME's (CreativeSME), Guimarães, Portugal (2009)

12. Souza, L., Ramos, I., Esteves, J.: Crowdsourcing Innovation: A Risk Management Approach. In: The Proceedings of the 4th Mediterranean Conference on Information Systems, Athens, Greece (2009)

13. Koulopoulos, T.M.: The innovation zone: How great companies re-innovate for amazing success. Nicholas Brealey Publishing, Mountain View (2009)

14. Diener, K., Piller, F.: The Market for Open Innovation: Increasing the Efficiency and Effectiveness of the Innovation Process. RWTH Group, Aachen (2010)

15. Vaishnavi, V.K., Kuechler, W.: Design Science Research Methods and Patterns: Innovating Information and Communication Technology. Auerbach Publications, Boca Raton (2007) 